\title{
Inheritance of Race-Specific Resistance to Xanthomonas campestris pv. campestris in Brassica Genomes
}

\author{
J. G. Vicente, J. D. Taylor, A. G. Sharpe, I. A. P. Parkin, D. J. Lydiate, and G. J. King
}

First, second, and sixth authors: Horticulture Research International, Wellesbourne, Warwick CV35 9EF, UK; and third, fourth, and fifth authors: Agriculture and Agri-Food Canada, Saskatoon Research Centre, 107 Science Place, Saskatoon SK S7N 0X2, Canada. Accepted for publication 6 June 2002.

\begin{abstract}
Vicente, J. G., Taylor, J. D., Sharpe, A. G., Parkin, I. A. P., Lydiate, D. J., and King, G. J. 2002. Inheritance of race-specific resistance to Xanthomonas campestris pv. campestris in Brassica genomes. Phytopathology 92:1134-1141.

The inheritance of resistance to three Xanthomonas campestris pv. campestris races was studied in crosses between resistant and susceptible lines of Brassica oleracea (C genome), B. carinata (BC genome), and $B$. napus (AC genome). Resistance to race 3 in the B. oleracea doubled haploid line $\mathrm{BOH} 85 \mathrm{c}$ and in PI 436606 was controlled by a single domi-

carinata line PI 199947. This resistance probably originates from the B genome. Resistance to race 4 in three $B$. napus lines, cv. Cobra, the rapid cycling line $\mathrm{CrGC5}$, and the doubled haploid line $\mathrm{N}-\mathrm{o}-1$, was controlled by a single dominant locus (Xca4). A set of doubled haploid lines, selected from a population used previously to develop a restriction fragment length polymorphism map, was used to map this locus. Xca4 was positioned on linkage group N5 of the B. napus A genome, indicating that this resistance originated from B. rapa. Xca4 is the first major locus to be mapped that controls race-specific resistance to $X$. campestris pv. campestris in Brassica spp.
\end{abstract} nant locus (Xca3). Resistance to races 1 and 3 in the B. oleracea line Badger Inbred-16 was quantitative and recessive. Strong resistance to races 1 and 4 was controlled by a single dominant locus (Xcal) in the $B$.
Additional keywords: black rot, cabbage, Ethiopian mustard, genetic mapping, oilseed rape, resistance genes.
Black rot of crucifers caused by Xanthomonas campestris pv. Campestris (Pammel) Dowson is the most important disease of Brassica oleracea (23). Six races of $X$. campestris pv. campestris currently are recognized and a gene-for-gene model recently was proposed to explain the interactions between races and differential cultivars (20). Worldwide, races 1 and 4 are the most important races in $B$. oleracea crops, especially in cabbage and cauliflower (20).

The control of black rot is difficult and can only be achieved by the use of disease-free seeds and cultural practices that limit the dissemination of the pathogen. Resistant cultivars could play an important role in reducing the losses due to the disease. Knowledge of inheritance of resistance is essential to the future success of breeding programs. Although previous studies have shown that the potentially most useful sources of resistance are present in the $\mathrm{A}$ and $\mathrm{B}$ genomes (B. rapa and B. nigra) and absent from the $\mathrm{C}$ genome (B. oleracea) $(1,7,17,22)$, the inheritance of resistance to $X$. campestris pv. campestris has been studied mainly in $B$. oleracea and without knowledge of existing races. Bain (2) attributed resistance in cabbage cv. Huguenot to one or more dominant genes. Williams et al. (25) proposed a trigenic model to explain the segregation of progenies derived from the Japanese cabbage cv. Early Fuji. According to this model, resistance was controlled by one major recessive gene and two modifiers. Resistance in seedlings of the cabbage accession PI 436606 (cv. Heh Yeh da Ping Tou) was attributed to one recessive gene (6), while the resistance of several accessions of cabbage and cauliflower appeared to be controlled by multiple genes $(15,18)$. Recently, quantitative trait loci (QTL), assumed to control resistance in Badger Inbred-16, a line derived from cv. Early Fuji, were mapped

Corresponding author: J. G. Vicente; E-mail address: joana.vicente@hri.ac.uk

Publication no. P-2002-0821-01R

(c) 2002 The American Phytopathological Society by Camargo et al. (5). Ignatov et al. (9) have attributed resistance to two $X$. campestris pv. campestris races (probably races 1 and 3 ) in $B$. oleracea to a recessive gene and to a dominant gene.

There have been only two studies concerning the inheritance of resistance to $X$. campestris pv. campestris in other Brassica species. Guo et al. (7) attributed the strong resistance found in accessions PI 199947 and PI 199949 to a single dominant gene and the moderate level of resistance of PI 273640 to a recessive gene. These accessions originally were thought to be $B$. napus, but have been re-identified as $B$. carinata (17). More recently, a study by Ignatov et al. (10) suggested that a single dominant gene controlled resistance to race 4 in B. rapa (e.g., cvs. Just Right Turnip and Seven Top Green Turnip) and in B. napus (cv. Cobra).

The objective of the present study was to elucidate the inheritance of race-specific resistance to X. campestris pv. campestris in a number of Brassica spp. accessions (Table 1). These accessions were selected after the broad screening exercise reported previously (17). In addition, we have attempted to clarify inheritance studies reported by other authors in the context of the postulated gene-for-gene model (20) and have determined the map position of a locus that controls resistance to race 4 in B. napus.

\section{MATERIALS AND METHODS}

Plant material. The accessions used in this work are presented in Table 1. At least one of the parents used for each of the $B$. oleracea and B. napus crosses was a doubled haploid (DH) line. In cases where DH lines were not available, selections obtained previously by selfing single plants were used.

Plants were raised from seeds sown in plastic pots with Levington $\mathrm{M} 2$ compost (The Scotts Company, Ipswich, UK) in a glasshouse with a minimum temperature of $20 / 15^{\circ} \mathrm{C}$ (day/night), venting at $22 / 17^{\circ} \mathrm{C}$, and supplementary lighting from October to March to give 16-h days. Eight-week-old plants of cabbage lines $\mathrm{BOH}$ 85c (DH line derived from cv. Böhmerwaldkohl), PI 436606 
(cv. Heh Yeh da Ping Tou), Badger Inbred-16 (BI-16 derived from cv. Early Fuji), and rape lines N-o-9 and Cobra were vernalized for 10 weeks at $4^{\circ} \mathrm{C}$. Other lines flowered without need of vernalization. The plants were transferred to a glasshouse with a minimum temperature of $15 / 10^{\circ} \mathrm{C}$ and venting at $18 / 12^{\circ} \mathrm{C}$ (day/night); the crosses were made in this glasshouse.

Parental lines were hybridized by bud pollination; cross pollination by insects was prevented by covering shoots with perforated polyethylene bags. All non-DH parental plants were self-pollinated to determine heterozygosity. Single plants of lines BOH 85 c, PI 436606 , and BI-16 were crossed to the susceptible DH line A12DHd as the female parent. Reciprocal crosses were made between a B. carinata line derived from PI 199947 and the susceptible line HRI 6987. Reciprocal crosses were also made between B. napus lines derived from Cobra, CrGC5, and N-o-1 and the susceptible DH line N-o-9. Crosses between Cobra and N-o-1 and CrGC5 and N-o-1 were also made. In most cases, $\mathrm{F}_{1}$ plants were vernalized by cold treatment, selfed to obtain an $F_{2}$ population, and backcrossed to parental lines. Vernalization was not required for B. carinata and for B. napus lines derived from the cross between CrGC5 and N-o-1.

A B. napus mapping population (N-o-72-8) of $\mathrm{DH}$ lines derived from a single $\mathrm{F}_{1}$ plant from an $\mathrm{N}-\mathrm{o}-9 \times \mathrm{N}-\mathrm{O}-1$ cross was used in this study (16). Thirty-four lines randomly selected from the population were used in the first assay. After analysis of the results, 13 additional lines were selected based on existing restriction fragment length polymorphism (RFLP) recombinant data to improve the accuracy of the mapping. Three plants were tested per line.

Disease assays. Plants were raised from seed sown in $9-\mathrm{cm}$ plastic pots filled with Levington M2. Pots were placed in a glasshouse under the conditions described previously. Four-week-old plants were inoculated with mouse tooth forceps following a method described previously (20). Race type strains of races 1, 3, and 4 described by Vicente et al. (20) were used in this study. The B. oleracea lines derived from the crosses A12DHd $\times \mathrm{BOH} 85 \mathrm{c}$ and A12DHd $\times$ PI 436606 were inoculated with the race 3 type strain, HRI 5212 (National Collection of Plant Pathogenic Bacteria 528). The $B$. oleracea lines derived from BI-16 were inoculated with the race 1 type strain, HRI 3811 (PHW 1205), and the race 3 type strain in separate leaves of the same plants. These plants were retested at 8 weeks with the race 1 type strain. Plants of the B. carinata lines were tested with the race 1 type strain and the race 4 type strain (HRI 1279A) in separate leaves of the same plants. The $B$. napus lines were inoculated with the race 4 type strain. Twenty-nine DH lines from the B. napus mapping population were tested with an additional race 4 isolate (HRI 6189). Inoculations with a single strain were made onto three leaves per plant; inoculations with two strains were made onto four leaves per plant, two with each strain. Approximately 10 to 12 points of inoculation were made per leaf.

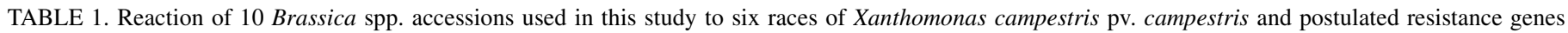
according to the gene-for-gene model $(17,20)$

\begin{tabular}{|c|c|c|c|c|c|c|c|c|c|c|}
\hline \multirow[b]{2}{*}{ Accession / line } & \multirow[b]{2}{*}{ Species } & \multirow[b]{2}{*}{ Reference } & \multirow[b]{2}{*}{ Type $^{\mathrm{a}}$} & \multirow{2}{*}{$\begin{array}{c}\text { Resistance } \\
\text { gene }\end{array}$} & \multicolumn{6}{|c|}{ Reaction with race ${ }^{b}$} \\
\hline & & & & & 1 & 2 & 3 & 4 & 5 & 6 \\
\hline A12DHd & B. oleracea & Bohuon et al. (3) & DH, Chinese kale & None & + & + & + & + & + & + \\
\hline $\mathrm{BOH} 85 \mathrm{c}$ & B. oleracea & Pink et al. (14) & DH, cabbage & R3 & + & $(+)$ & - & + & - & + \\
\hline PI 436606 / 01 & B. oleracea & Hunter et al. (8) & SPS, cabbage & R3 & + & $(+)$ & - & + & - & $(+)$ \\
\hline BI-16 & B. oleracea & Camargo et al. (5) & Ib, cabbage & $\mathrm{R} 6 ?$ & $(+)$ & $(+)$ & $(+)$ & + & $(+)$ & $(+)$ \\
\hline HRI 6987 & B. carinata & This study & OP, Ethiopian mustard & None & + & nt & + & + & + & + \\
\hline PI 199947 / 07 & B. carinata & Guo et al. (7); Vicente et al. (20) & SPS, Ethiopian mustard & $\mathrm{R} 1$ & - & + & - & - & + & + \\
\hline $\mathrm{N}-\mathrm{o}-9$ & B. napus & Sharpe et al. (16) & $\mathrm{DH}$, winter rape & None & + & + & + & + & + & + \\
\hline Cobra / 14R & B. napus & Vicente et al. (20) & SPS, winter rape & R4 & + & $(+)$ & $\mathrm{v}$ & - & + & + \\
\hline CrGC5 / 02 & B. napus & Williams and Hill (24) & SPS, rapid cycling & $\mathrm{R} 4$ & + & + & + & $(+)$ & + & + \\
\hline $\mathrm{N}-\mathrm{O}-1$ & B. napus & Sharpe et al. (16) & $\mathrm{DH}$, spring rape & $\mathrm{R} 4$ & + & + & + & $(+)$ & + & + \\
\hline
\end{tabular}

${ }^{a} \mathrm{DH}$, doubled haploid line; OP, open pollinated; SPS, single plant selection from open pollinated line; Ib, inbred line.

b +, susceptible; (+), partially resistant; -, resistant; nt, not tested; v, variable.

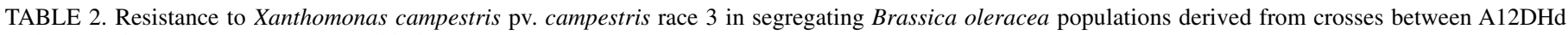
and $\mathrm{BOH} 85 \mathrm{c}$ and A12DHd and PI 436606

\begin{tabular}{|c|c|c|c|c|c|c|c|c|c|c|c|c|}
\hline & & \multicolumn{8}{|c|}{ Number of plants ${ }^{b}$} & \multirow{4}{*}{$\begin{array}{l}\text { Observed } \\
\text { ratio (R:S) }\end{array}$} & \multirow{4}{*}{$\begin{array}{l}\text { Proposed } \\
\text { ratio }(\mathrm{R}: \mathrm{S})\end{array}$} & \multirow{4}{*}{$\begin{array}{c}\chi^{2} \\
\text { probability }\end{array}$} \\
\hline & & & & Partiall & sistant & Sus & tible & Highly & ptible & & & \\
\hline & & $0-1$ & & & & & & & 9 & & & \\
\hline \multicolumn{2}{|c|}{ Parental lines and crosses ${ }^{\mathrm{a}}$} & - & $<25 \%$ & $\geq 25 \%$ & $<50 \%$ & $\geq 50 \%$ & $<75 \%$ & $\geq 75 \%$ & - & & & \\
\hline $\mathrm{P}$ & A12DHd & - & - & - & - & 2 & 5 & 2 & 5 & $0: 14$ & $0: 1$ & - \\
\hline $\mathrm{P}$ & $\mathrm{BOH} 85 \mathrm{c}$ & $\underline{4}$ & $\underline{3}$ & - & $\underline{1}$ & - & - & - & - & $8: 0$ & $1: 0$ & - \\
\hline $\mathrm{F}_{1}$ & A12DHd $\times$ BOH $85 c$ & - & $\underline{11}$ & $\underline{2}$ & $\underline{2}$ & - & - & - & - & $15: 0$ & $1: 0$ & - \\
\hline $\mathrm{F}_{2}$ & A12DHd $\times$ BOH $85 c$ & $\underline{25}$ & $\underline{27}$ & $\underline{4}$ & $\underline{5}$ & - & 3 & 1 & 7 & $61: 11$ & $3: 1$ & 0.06 \\
\hline Bs & A12DHd $\times \mathrm{F}_{1}$ & $\underline{10}$ & $\underline{8}$ & $\underline{1}$ & - & - & 3 & 9 & 16 & $19: 28$ & $1: 1$ & 0.19 \\
\hline $\mathrm{Br}$ & $\mathrm{BOH} 85 \mathrm{c} \times \mathrm{F}_{1}$ & $\underline{12}$ & $\underline{2 \overline{7}}$ & $\underline{2}$ & $\underline{2}$ & - & - & - & - & $43: 0$ & $1: 0$ & - \\
\hline $\mathrm{P}$ & A12DHd & - & - & - & - & - & - & 7 & 3 & $0: 10$ & $0: 1$ & - \\
\hline $\mathrm{S}_{1}$ & PI 436606 & $\underline{5}$ & $\underline{10}$ & $\underline{6}$ & - & 1 & 1 & - & - & $21: 2$ & $3: 1$ & 0.07 \\
\hline $\mathrm{F}_{1}$ & A12DHd $\times$ PI 436606 & $\underline{1}$ & $\underline{5}$ & $\underline{1}$ & $\underline{6}$ & 1 & 3 & 4 & 8 & $13: 16$ & $1: 1$ & 0.58 \\
\hline $\mathrm{F}_{2}$ & $\begin{array}{l}\text { A } 12 \text { DHd } \times \text { PI } 436606 \\
\left(\text { from res. } F_{1}\right)^{c}\end{array}$ & $\underline{15}$ & $\underline{28}$ & - & $\underline{7}$ & - & 11 & - & 10 & $50: 21$ & $3: 1$ & 0.37 \\
\hline Bs & A12DHd $\times$ res. $F_{1}$ & $\underline{13}$ & $\underline{16}$ & $\underline{1}$ & $\underline{1}$ & 2 & 11 & 1 & 6 & $31: 20$ & $1: 1$ & 0.12 \\
\hline $\mathrm{Br}$ & PI $436606 \times$ res. $F_{1}$ & $\underline{13}$ & $\underline{4}$ & $\underline{1}$ & $\underline{2}$ & - & 5 & - & 1 & $20: 6$ & $3: 1$ & 0.82 \\
\hline
\end{tabular}

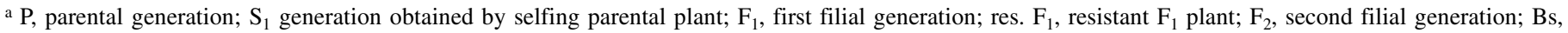
backcross to susceptible parent; Br, backcross to resistant parent.

b In each class, based on a 0-to-9 scale of severity and percentage of infected points per plant. Underlined plants were considered resistant.

c A resistant $\mathrm{F}_{1}$ plant was self-pollinated. 
Scoring of resistance. The results were recorded 2 and 3 weeks after inoculation. The total number of inoculated points and the number of points showing symptoms were recorded and the percentage of infected points was calculated. The severity of symptoms was assessed on a six-point scale of 0 to 9 based on the relative lesion size ( 0 , no symptoms; 1 , small necrosis or chlorosis surrounding the infection point; 3, typical small V-shaped lesion with black veins; 5 , typical lesion half way to the middle vein; 7 , typical lesion progressing to the middle vein; and 9, lesion reaching the middle vein).

Segregation analysis. Plants were grouped into eight categories (Table 2) based on resistance scores and percentage of inoculated points showing symptoms. Generally, plants with a score of 0,1 , or 3 with less than $25 \%$ of points showing symptoms were considered resistant; plants with a score of 3 with more than $25 \%$ of points showing symptoms and with a score of 5 with less than $50 \%$ of points showing symptoms were considered partially resistant; plants with a score of 5 with more than $50 \%$ of points showing symptoms and with a score of 7 with less than $75 \%$ of points showing symptoms were considered susceptible; and plants with a score of 7 with more than $75 \%$ of points showing symptoms and with a score of 9 were considered very susceptible. The overall distinction between resistance and susceptibility in lines derived from the crosses was made by comparison with the reaction of the parental lines. In most cases, there was a clear distinction between resistant and susceptible plants, but in some cases (e.g., segregants from BI-16 that showed partial resistance) the response was more quantitative, with many plants showing intermediate scores. Chisquare $\left(\chi^{2}\right)$ goodness of fit was used to test the hypothesis that one locus controls resistance in the crosses, according to the segregation ratios expected for the $F_{2}(3: 1$ or $1: 3)$ backcross to the resistant or the susceptible parent $(1: 1)$ and $\mathrm{F}_{1}$-derived DH lines $(1: 1)$.

The results obtained in inoculations of segregating populations ( $F_{2}$ and backcrosses to the resistant or susceptible parent) with two different races and the results of inoculations at 4 and 8 weeks were compared through linear regression analysis using GenStat 5th edition, release 4.21 (Rothamsted Experimental Station, UK). The angular transformation of the percentage of points with symptoms and the resistance scores were analyzed separately. The independence of segregation and flower color in $\mathrm{F}_{2}$ and backcross to the resistant parent populations derived from crosses with BI-16 was tested with $t$ tests (for transformed percentage of points with symptoms) and Mann-Whitney U tests (for resistance scores).

Linkage analysis of qualitative segregation of resistance symptoms in B. napus was carried out in conjunction with segregation data for RFLP markers used previously to develop a linkage map for a DH population (16). The data were analyzed with the program MAPMAKER v.3.0 (Whitehead Institute for Biomedical Research) (13) with a minimum LOD (log of the odds ratio of linkage versus no linkage) score of 3.0. Distances were expressed in centimorgans using Kosambi's map function (12).

\section{RESULTS}

Inheritance of resistance in $\boldsymbol{B}$. oleracea. The resistance of lines derived from a cross between A12DHd and $\mathrm{BOH} 85 \mathrm{c}$ and a cross between A12DHd and PI 436606 to X. campestris pv. campestris race 3 is presented in Table 2.

The parental $\mathrm{DH}$ line $\mathrm{BOH} 85 \mathrm{c}$ was either resistant or partially resistant to $X$. campestris pv. campestris race 3, whereas A12DHd was susceptible or highly susceptible. Plants were considered resistant if they had a score of $0,1,3$, or 5 with less than $50 \%$ of inoculated points showing symptoms of the disease. The $F_{1}$ of the cross A12DHd $\times \mathrm{BOH} 85 \mathrm{c}$ and the backcross to the resistant parent had a resistant phenotype. The $\mathrm{F}_{2}$ and the backcross to the susceptible parent segregated clearly. The segregation ratios were consistent with the hypothesis that resistance was controlled by a single dominant locus (Xca3) (Table 2).

The PI 436606 line was either resistant or partially resistant to $X$. campestris pv. campestris race 3 . The criterion for distinguish-

TABLE 3. Resistance to Xanthomonas campestris pv. campestris races 1 and 3 in segregating Brassica oleracea populations derived from two crosses between A12DHd and BI-16

\begin{tabular}{|c|c|c|c|c|c|c|c|c|c|c|c|c|c|}
\hline \multirow[b]{4}{*}{ Race } & & & \multicolumn{8}{|c|}{ Number of plants ${ }^{\mathrm{b}}$} & \multirow{4}{*}{$\begin{array}{c}\text { Observed } \\
\text { ratio }(\mathrm{R}: \mathrm{S})\end{array}$} & \multirow{4}{*}{$\begin{array}{l}\text { Proposed } \\
\text { ratio (R:S) }\end{array}$} & \multirow{4}{*}{$\begin{array}{c}\chi^{2} \\
\text { probability }\end{array}$} \\
\hline & & & \multicolumn{2}{|c|}{ Resistant } & \multicolumn{2}{|c|}{ Partial } & \multicolumn{2}{|c|}{ Susceptible } & \multicolumn{2}{|c|}{ Very susceptible } & & & \\
\hline & & & $0-1$ & & & & & & & 9 & & & \\
\hline & \multicolumn{2}{|c|}{ Parental lines and crosses ${ }^{\mathrm{a}}$} & - & $<25 \%$ & $\geq 25 \%$ & $<50 \%$ & $\geq 50 \%$ & $<75 \%$ & $\geq 75 \%$ & - & & & \\
\hline 1 & $\mathrm{P}$ & A12DHd & - & - & - & - & - & - & 4 & 7 & $0: 11$ & $0: 1$ & - \\
\hline 3 & $\mathrm{P}$ & A12DHd & - & - & - & - & 1 & 2 & 2 & 6 & $0: 11$ & $0: 1$ & - \\
\hline 1 & $\mathrm{~S}_{1}$ & BI-16 plant A & $\underline{3}$ & 4 & 2 & $\underline{3}$ & - & - & - & - & $12: 0$ & 1:0 & - \\
\hline 3 & $\mathrm{~S}_{1}$ & BI-16 plant A & $\underline{\overline{6}}$ & $\underline{\overline{3}}$ & $\underline{\overline{2}}$ & $\underline{1}$ & - & - & - & - & $12: 0$ & $1: 0$ & - \\
\hline 1 & $F_{1}$ & A12DHd $\times$ BI- 16 plant $A$ & - & - & - & - & - & 3 & 2 & 8 & $0: 13$ & $0: 1$ & - \\
\hline 3 & $\mathrm{~F}_{1}$ & A12DHd $\times$ BI-16 plant A & - & - & - & - & 1 & 6 & 2 & 4 & $0: 13$ & $0: 1$ & - \\
\hline 1 & $\mathrm{~F}_{2}$ & A12DHd $\times$ BI-16 plant A & - & - & $\underline{1}$ & $\underline{6}$ & 3 & 11 & 16 & 29 & $7: 59$ & $1: 3$ & 0.01 \\
\hline 3 & $\mathrm{~F}_{2}$ & A12DHd $\times$ BI- 16 plant $A$ & - & $\underline{5}$ & $\overline{1}$ & $\overline{7}$ & 2 & 26 & 5 & 20 & $13: 53$ & $1: 3$ & 0.32 \\
\hline 1 & $\mathrm{Br}$ & BI-16 pl. A $\times \mathrm{F}_{1}$ & $\underline{1}$ & $\overline{\underline{z}}$ & $\underline{\overline{6}}$ & $\underline{14}$ & 3 & 11 & 7 & 9 & $28: 30$ & $1: 1$ & 0.79 \\
\hline 3 & $\mathrm{Br}$ & $\mathrm{BI}-16 \mathrm{pl} . \mathrm{A} \times \mathrm{F}_{1}$ & $\overline{4}$ & 10 & $\underline{3}$ & $\overline{14}$ & 2 & 19 & - & 6 & $31: 27$ & $1: 1$ & 0.60 \\
\hline 1 & Bs & $\mathrm{A} 12 \mathrm{DHd} \times \mathrm{F}_{1}$ & $\overline{-}$ & - & - & - & - & 2 & 9 & 13 & $0: 24$ & $0: 1$ & - \\
\hline 3 & Bs & $\mathrm{A} 12 \mathrm{DHd} \times \mathrm{F}_{1}$ & - & - & - & - & 4 & 4 & 8 & 8 & $0: 24$ & $0: 1$ & - \\
\hline 1 & $P$ & A12DHd & - & - & - & - & - & - & 5 & 3 & $0: 8$ & $0: 1$ & - \\
\hline 3 & $\mathrm{P}$ & A12DHd & - & - & - & 1 & 3 & 3 & 1 & - & $1: 7$ & $0: 1$ & - \\
\hline 1 & $\mathrm{~S}_{1}$ & BI- 16 plant $B$ & $\underline{3}$ & $\underline{3}$ & $\underline{2}$ & $\underline{1}$ & - & - & - & - & $9: 0$ & $1: 0$ & - \\
\hline 3 & $\mathrm{~S}_{1}$ & BI- 16 plant B & $\underline{4}$ & $\underline{2}$ & $\underline{1}$ & $\underline{2}$ & - & - & - & - & $9: 0$ & $1: 0$ & - \\
\hline 1 & $\mathrm{~F}_{1}$ & A12DHd $\times$ BI-16 plant B & - & $=$ & - & - & - & 5 & 2 & 5 & $0: 12$ & $0: 1$ & - \\
\hline 3 & $\mathrm{~F}_{1}$ & A12DHd $\times$ BI-16 plant B & - & - & - & $\underline{2}$ & - & - & 7 & 3 & $2: 10$ & $0: 1$ & - \\
\hline 1 & $\mathrm{~F}_{2}$ & A12DHd $\times$ BI- 16 plant $B$ & - & $\underline{3}$ & $\underline{2}$ & $1 \overline{3}$ & 5 & 19 & 8 & 18 & $18: 50$ & $1: 3$ & 0.78 \\
\hline 3 & $\mathrm{~F}_{2}$ & A12DHd $\times$ BI-16 plant B & $\underline{3}$ & $\underline{5}$ & $\underline{2}$ & $\underline{20}$ & 4 & 22 & 1 & 11 & $30: 38$ & $1: 3$ & 0.00 \\
\hline 1 & $\mathrm{Br}$ & $\mathrm{BI}-16 \mathrm{pl} . \mathrm{B} \times \mathrm{F}_{1}$ & - & $\underline{11}$ & $\underline{1}$ & $\underline{18}$ & - & 16 & 2 & 11 & $30: 29$ & $1: 1$ & 0.90 \\
\hline 3 & $\mathrm{Br}$ & $\mathrm{BI}-16 \mathrm{pl} . \mathrm{B} \times \mathrm{F}_{1}$ & $\underline{1}$ & $\underline{20}$ & $\underline{1}$ & $\underline{16}$ & - & 19 & - & 2 & $38: 21$ & $1: 1$ & 0.03 \\
\hline 1 & Bs & A12DHd $\times \mathrm{F}_{1}$ & - & - & - & - & 1 & 2 & 10 & 12 & $0: 25$ & $0: 1$ & - \\
\hline 3 & Bs & $\mathrm{A} 12 \mathrm{DHd} \times \mathrm{F}_{1}$ & - & - & $\underline{1}$ & - & 5 & 8 & 2 & 9 & $1: 24$ & $0: 1$ & - \\
\hline
\end{tabular}

${ }^{a} \mathrm{P}$, parental generation; $\mathrm{S}_{1}$ generation obtained by selfing parental plant; $\mathrm{F}_{1}$, first filial generation; $\mathrm{F}_{2}$, second filial generation; Bs, backcross to susceptible parent; $\mathrm{Br}$, backcross to resistant parent.

${ }^{\mathrm{b}}$ In each class, based on a 0 -to-9 scale of severity and percentage of infected points per plant. Underlined plants were considered resistant. 
ing between resistant and susceptible plants was as described previously, although results were less clear-cut (Table 2). Plants derived from a self of the parental PI 436606 plant used in the crosses segregated for resistance. In addition, the $\mathrm{F}_{1}$ derived from a cross between A12DHd and PI 436606 also segregated, indicating that the parental PI 436606 plant was heterozygous. The segregation of an $F_{2}$ population derived from a resistant $F_{1}$ plant and of the backcross populations indicates that resistance was controlled by a single dominant locus.

The resistance of lines derived from two crosses between A12DHd and BI-16 to X. campestris pv. campestris races 1 and 3 is presented in Table 3. BI-16 was either resistant or partially resistant to races 1 and 3, whereas A12DHd was susceptible or highly susceptible. The $F_{1}$ plants and the plants resulting from a backcross to the susceptible parent were susceptible or highly susceptible. Results with the $\mathrm{F}_{2}$ and the backcross to the resistant parent populations were highly variable. In these populations, the difference between resistant and susceptible plants was not clearcut, and a large number of plants were classified in intermediate categories. Plants were considered resistant if they had a score of $0,1,3$, or 5 with less than $50 \%$ of inoculated points showing symptoms of the disease. The segregation patterns indicate that resistance was mainly controlled by one recessive locus (xca6) or by linked loci.

The results obtained by inoculating the race 3 strain into segregating populations ( $\mathrm{F}_{2}$ and backcross to the resistant parent) derived from crosses with BI-16 were compared with those obtained by inoculating them with race 1 (Fig. 1). There was no need of an interception constant in the regression of the first experiment, but a constant improved the regression of the second experiment. In both cases, the slopes of the regression lines are significantly lower than 1 . These results indicate that the plants were generally more susceptible to race 1 than to race 3 . The analysis of resistance scores was generally consistent with the analysis of percentage of points with symptoms (data not shown). The amount of disease seen when 8 -week-old plants were inoculated with race 1 was correlated with the amount seen when plants were inoculated at 4 weeks $(r=0.68$ and 0.70 for experiments 1 and 2 , respectively). The slopes of the regressions of the transformed percentage of points $(0.61$ and 0.74$)$ were significantly lower than 1 in both experiments, indicating that the plants were generally less susceptible at 8 weeks (data not shown).

Plants of BI-16 had yellow flowers, while plants of A12DHd had white flowers. The $F_{1}$ plants and the backcross to the susceptible parent populations had white flowers. The $\mathrm{F}_{2}$ and backcross to the resistant parent populations segregated. The locus flower that controls the color of the flowers has previously been mapped in linkage group O3 (3). This linkage group corresponds to linkage group LG1 (T. Osborn, personal communication) where QTL for BI-16 resistance have been mapped $(4,5)$. For this reason, the linkage between flower color and resistance was tested. The mean of the transformed percentage of points with symptoms of plants with white flowers was significantly greater than the mean for plants with yellow flowers in one of the $F_{2}$ populations (first experiment) and in the two backcrosses to the resistant parent populations. The mean of the scores of these populations was also significantly different, except in the case of the $F_{2}$ of the second experiment (data not shown). These results indicate that resistance was not independent of the flower color.

The $\mathrm{F}_{1}$ plants derived from crosses between $\mathrm{BI}-16$ and $\mathrm{BOH}$ $85 \mathrm{c}$ were susceptible to race 1 (as is $\mathrm{BOH} 85 \mathrm{c}$ ) and resistant to race 3 (Table 4), suggesting that the loci Xca3 and $x c a 6$ are not linked. The $\mathrm{F}_{1}$ plants derived from crosses between PI 436606 and $\mathrm{BOH} 85 \mathrm{c}$ were resistant to race 3 (data not shown). Resistance in these two lines might be controlled by the same locus (Xca3) or by different loci.

Inheritance of resistance in $\boldsymbol{B}$. carinata. The resistance of lines derived from a cross between HRI 6987 and PI 199943 to $X$. campestris pv. campestris races 1 and 4 is presented in Table 5. PI 199947 showed strong resistance to X. campestris pv. campestris races 1 and 4 . Plants were considered resistant if they had a score of 0,1 , or 3 with less than $25 \%$ of inoculated points showing symptoms of the disease. The $\mathrm{F}_{1}$ plants were resistant although a few small lesions were observed in a number of the plants. Plants from the backcross to the resistant parent were uniformly resistant. The clear segregation of the $F_{2}$ and backcross to the susceptible parent indicate that resistance was probably controlled by a single dominant locus (Xcal).

Resistance to race 4 was strongly correlated with resistance to race 1 in the $F_{2}$ and backcross to the susceptible parent populations, indicating that resistance was controlled by the same locus (Xcal) or by closely linked loci (Fig. 2). There was no need of an interception constant in the regression. The slope of the regression line was significantly lower than 1 , indicating that the plants were generally more susceptible to race 1 than to race 4 . The analysis of the results of resistance scores was consistent with the analysis of percentage of infected points (data not shown).

Inheritance of resistance in B. napus. The resistance of lines derived from crosses between the susceptible line N-o-9 and the resistant lines $\mathrm{N}-\mathrm{o}-1$, Cobra, and $\mathrm{CrGC5}$ to $X$. campestris pv. campestris race 4 is presented in Table 6 . Cobra was very resistant to race 4, whereas N-o-1 and CrGC5 plants were less resistant and
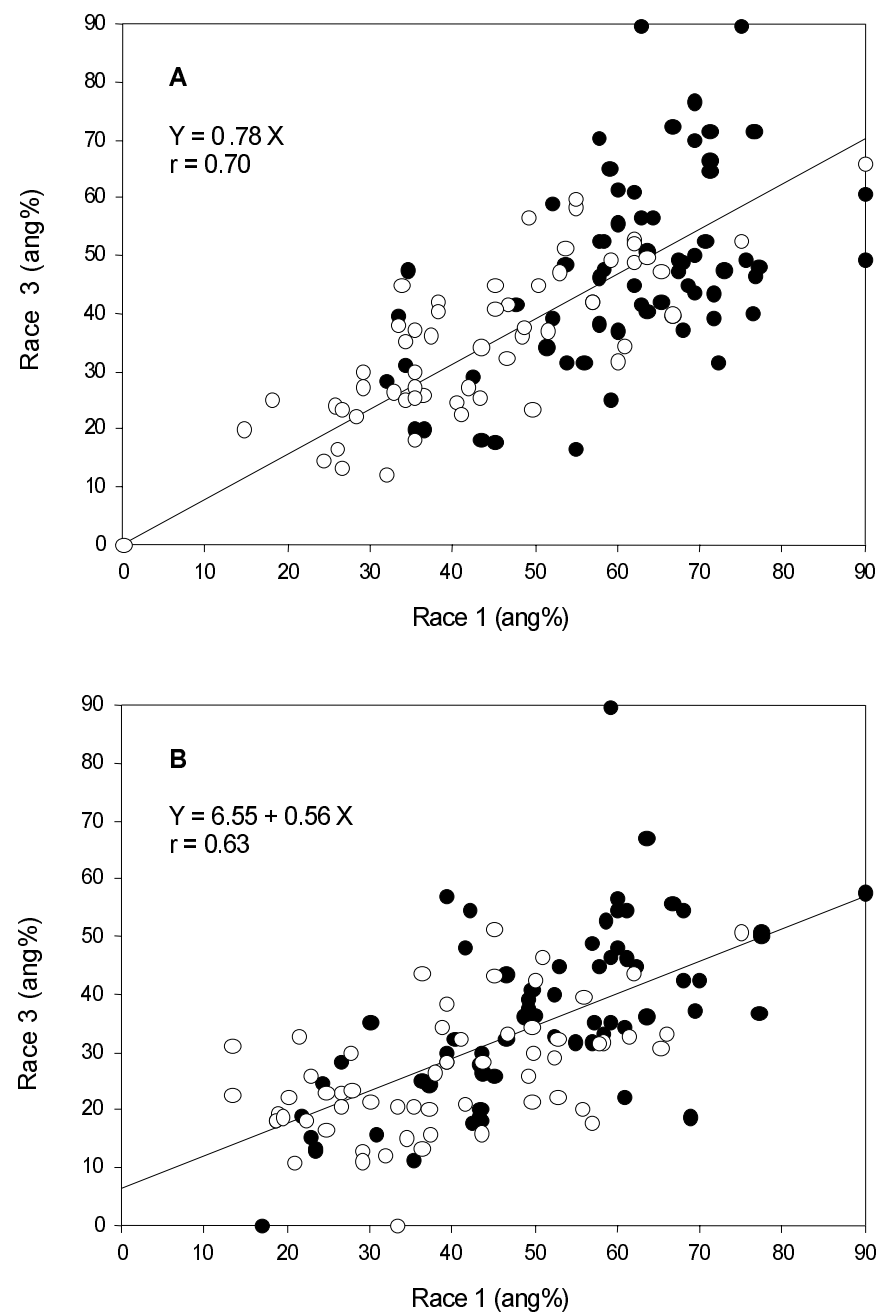

Fig. 1. Relation between the angular transformation of the percentage of points showing disease symptoms in plants of the $F_{2}$ (filled circle) and backcross to the resistant parent (open circle) populations derived from crosses between Brassica oleracea line A12DHd and BI-16 inoculated with races 1 and 3 of Xanthomonas campestris pv. campestris. A, First experiment; B, second experiment. 
often had small lesions. Plants derived from crosses involving No- 1 and Cobra were considered resistant if they had a score of 0 , 1 , or 3 with less than $25 \%$ of inoculated points showing symptoms of the disease. Plants derived from crosses involving CrGC5 were considered resistant if they had a score of $0,1,3$, or 5 with less than $50 \%$ of inoculated points showing symptoms of the disease. The $\mathrm{F}_{1}$ and backcross to the resistant parent populations were resistant, although some lesions were observed in a number of plants derived from crosses involving $\mathrm{N}-\mathrm{o}-1$ and $\mathrm{CrGC5}$. The clear segregation of the $\mathrm{F}_{2}$ and backcross to the susceptible parent indicated that resistance was probably controlled by a single dominant locus $(\mathrm{Xca} 4)$ in each of the three cases.

Tests of allelism of resistance to race 4 in B. napus were made in crosses between $\mathrm{N}-\mathrm{O}-1$ and Cobra and $\mathrm{N}-\mathrm{O}-1$ and CrGC5. There was no evidence of segregation in $\mathrm{F}_{1}, \mathrm{~F}_{2}$, and backcrosses to each parent population derived from the cross between $\mathrm{N}-\mathrm{o}-1$ and Cobra, with all plants tested $\left(27 \mathrm{~F}_{1}, 28 \mathrm{~F}_{2}\right.$, and 15 of each backcross) having a score of 0 or 1 . There was no evidence of segregation in $F_{1}$ and $F_{2}$ populations derived from the cross between CrGC5 and N-o-1, with all plants tested $\left(28 \mathrm{~F}_{1}\right.$ and $\left.26 \mathrm{~F}_{2}\right)$ having scores of 0,1 , or 3 with less than $25 \%$ of points showing symptoms. Although the number of plants tested was insufficient to disprove the possibility of multiple loci, resistance in $\mathrm{N}-\mathrm{o}-1$, Cobra, and CrGC5 was most probably controlled by the same locus (Xca4).

The map location of the Xca4 locus was established through the screening of an existing DH mapping population derived from a cross between N-o-9 and N-o-1 (16). The initial screen on $34 \mathrm{DH}$ lines produced a segregation of 18:16 (R:S). Based on a preliminary map position, 13 additional $\mathrm{DH}$ lines were selected to be screened to improve the accuracy of mapping. The second screen produced a segregation of $6: 7(\mathrm{R}: \mathrm{S})$. The overall segregation in the DH lines tested was $24: 23$ ( $\chi^{2}$ probability of 0.88 for a segregation of 1:1), indicating that resistance was controlled by a single locus. In addition, $29 \mathrm{DH}$ lines were tested with a different strain of race 4 (HRI 6189). The segregation of these lines was similar to the segregation obtained with the race 4 type strain (HRI 1279A). Based on the results of the segregation of the $47 \mathrm{DH}$ lines, the locus $\mathrm{Xca} 4$ was positioned in a mapping interval at one end of linkage group N5 of the B. napus A genome (Fig. 3).

TABLE 4. Test of allelism of resistance to Xanthomonas campestris pv. campestris races 1 and 3 in $\mathrm{F}_{1}$ Brassica oleracea populations derived from crosses between BI-16 and $\mathrm{BOH} 85 \mathrm{c}$

\begin{tabular}{|c|c|c|c|c|c|c|c|c|c|c|c|}
\hline & & & \multicolumn{8}{|c|}{ Number of plants ${ }^{b}$} & \multirow{3}{*}{$\begin{array}{l}\text { Observed } \\
\text { ratio }(\mathrm{R}: \mathrm{S})\end{array}$} \\
\hline & & & \multirow{2}{*}{\multicolumn{2}{|c|}{ Resistant }} & \multicolumn{2}{|c|}{ Partially resistant } & \multicolumn{2}{|c|}{ Susceptible } & \multicolumn{2}{|c|}{ Highly susceptible } & \\
\hline & & & & & & & & & & 9 & \\
\hline 1 & $\mathrm{P}$ & $\mathrm{BOH} 85 \mathrm{c}$ & - & - & - & - & 1 & 1 & 2 & 2 & $0: 6$ \\
\hline 3 & $\mathrm{P}$ & $\mathrm{BOH} 85 \mathrm{c}$ & $\underline{4}$ & - & 1 & - & 1 & - & - & - & $5: 1$ \\
\hline 1 & $\mathrm{P}$ & BI-16 & $\overline{2}$ & 4 & $\overline{3}$ & 2 & - & - & - & - & $11: 0$ \\
\hline 1 & $\mathrm{~F}_{1}$ & BI-16 pl. A × BOH85c & - & - & - & - & 1 & 4 & 7 & 12 & $0: 24$ \\
\hline 3 & $\mathrm{~F}_{1}$ & BI-16 pl. A $\times$ BOH $85 \mathrm{c}$ & 9 & 12 & - & $\underline{3}$ & - & - & - & - & 24:0 \\
\hline 1 & $\mathrm{~F}_{1}$ & $\mathrm{BOH} 85 \mathrm{c} \times \mathrm{BI}-16$ plant $\mathrm{B}$ & - & - & - & $\underline{1}$ & 1 & 14 & 1 & 10 & $1: 26$ \\
\hline 3 & $\mathrm{~F}_{1}$ & $\mathrm{BOH} 85 \mathrm{c} \times \mathrm{BI}-16$ plant $\mathrm{B}$ & $\underline{8}$ & $\underline{15}$ & $\underline{4}$ & - & - & - & - & - & $27: 0$ \\
\hline 1 & $\mathrm{~F}_{1}$ & BI-16 pl. B × BOH 85c & - & - & - & $\underline{3}$ & - & 19 & 1 & 5 & $3: 25$ \\
\hline 3 & $\mathrm{~F}_{1}$ & BI-16 pl. B $\times$ BOH 85c & $\underline{6}$ & $\underline{12}$ & $\underline{6}$ & $\underline{4}$ & - & - & - & - & 28:0 \\
\hline
\end{tabular}

${ }^{a} \mathrm{P}$, parental generation; $\mathrm{F}_{1}$, first filial generation.

${ }^{\mathrm{b}}$ In each class, based on a 0 -to- 9 scale of severity and percentage of infected points per plant. Underlined plants were considered resistant.

TABLE 5. Resistance to Xanthomonas campestris pv. campestris races 1 and 4 in segregating Brassica carinata populations derived from crosses between PI 199947 and HRI 6987

\begin{tabular}{|c|c|c|c|c|c|c|c|c|c|c|c|c|}
\hline \multirow[b]{4}{*}{ Race } & \multirow[b]{4}{*}{ Parental lines and crosses ${ }^{\mathrm{a}}$} & \multicolumn{8}{|c|}{ Number of plants ${ }^{b}$} & \multirow{4}{*}{$\begin{array}{l}\text { Observed } \\
\text { ratio }(\mathrm{R}: \mathrm{S})\end{array}$} & \multirow{4}{*}{$\begin{array}{c}\text { Proposed } \\
\text { ratio }(\mathrm{R}: \mathrm{S})\end{array}$} & \multirow{4}{*}{$\begin{array}{c}\chi^{2} \\
\text { probability }\end{array}$} \\
\hline & & \multirow{3}{*}{$\frac{\text { Res }}{\frac{0-1}{-}}$} & \multicolumn{3}{|c|}{$\begin{array}{l}\text { Partially } \\
\text { resistant }\end{array}$} & \multicolumn{2}{|c|}{ Susceptible } & \multicolumn{2}{|c|}{$\begin{array}{c}\text { Highly } \\
\text { susceptible }\end{array}$} & & & \\
\hline & & & & & & & & & 9 & & & \\
\hline & & & $<25 \%$ & $\geq 25 \%$ & $<50 \%$ & $\geq 50 \%$ & $<75 \%$ & $\geq 75 \%$ & - & & & \\
\hline 1 & $\mathrm{~S}_{1} \quad$ PI 199947 & $\underline{11}$ & - & - & - & - & - & - & - & 11:0 & $1: 0$ & - \\
\hline 4 & $\mathrm{~S}_{1} \quad$ PI 199947 & 11 & _- & - & _- & _- & _- & - & - & 11:0 & $1: 0$ & - \\
\hline 1 & $\mathrm{~S}_{1} \quad$ HRI 6987 & - & - & - & - & 1 & 1 & - & 11 & $0: 13$ & $0: 1$ & - \\
\hline 4 & $\mathrm{~S}_{1} \quad$ HRI 6987 & - & - & - & - & 1 & 6 & - & 6 & $0: 13$ & $0: 1$ & - \\
\hline 1 & $\mathrm{~F}_{1} \quad$ HRI $6987 \times$ PI 199947 & $\underline{6}$ & $\underline{6}$ & - & - & - & - & - & - & $12: 0$ & $1: 0$ & - \\
\hline 4 & $\mathrm{~F}_{1} \quad$ HRI $6987 \times$ PI 199947 & $\underline{9}$ & $\underline{3}$ & - & - & - & - & - & - & $12: 0$ & $1: 0$ & - \\
\hline 1 & $\mathrm{~F}_{1} \quad$ PI $199947 \times 6987$ & 9 & 2 & - & - & - & - & - & - & 11:0 & $1: 0$ & - \\
\hline 4 & $\mathrm{~F}_{1} \quad$ PI $199947 \times 6987$ & $\underline{10}$ & $\underline{1}$ & - & - & - & - & - & - & $11: 0$ & $1: 0$ & - \\
\hline 1 & $\mathrm{~F}_{2} \quad$ HRI $6987 \times$ PI 199947 & $\underline{26}$ & $\underline{8}$ & - & - & 2 & 3 & - & 8 & $34: 13$ & $3: 1$ & 0.67 \\
\hline 4 & $\mathrm{~F}_{2} \quad$ HRI $6987 \times$ PI 199947 & $\overline{31}$ & $\overline{3}$ & - & 2 & 1 & 5 & 1 & 4 & $34: 13$ & $3: 1$ & 0.67 \\
\hline 1 & $\mathrm{Br} \quad$ PI $199947 \times\left(\right.$ HRI $6987 \times$ PI 199947) $\mathrm{F}_{1}$ & $\underline{12}$ & - & - & - & - & - & - & - & $12: 0$ & $1: 0$ & - \\
\hline 4 & $\mathrm{Br}$ PI $199947 \times\left(\right.$ HRI $6987 \times$ PI 199947) $\mathrm{F}_{1}$ & $\overline{12}$ & - & - & - & - & - & - & - & $12: 0$ & 1:0 & - \\
\hline 1 & Bs $\quad$ HRI $6987 \times\left(\right.$ HRI $6987 \times$ PI 199947) $\mathrm{F}_{1}$ & $\overline{7}$ & $\underline{9}$ & - & 1 & 1 & 4 & 4 & 9 & $16: 19$ & $1: 1$ & 0.61 \\
\hline 4 & Bs HRI $6987 \times($ HRI $6987 \times$ PI 199947$) \mathrm{F}_{1}$ & $\underline{10}$ & $\underline{6}$ & - & 1 & 1 & 13 & - & 4 & $16: 19$ & $1: 1$ & 0.61 \\
\hline
\end{tabular}

${ }^{a} S_{1}$ generation obtained by selfing parental plant; $F_{1}$, first filial generation; $F_{2}$, second filial generation; Bs, backcross to susceptible parent; Br, backcross to resistant parent.

${ }^{b}$ In each class, based on a 0-to-9 scale of severity and percentage of infected points per plant. Underlined plants were considered resistant. 


\section{DISCUSSION}

In previous studies $(17,20)$, we developed a gene-for-gene model to explain the relationship between brassicas and six races of $X$. campestris pv. campestris and we have identified a number of sources of resistance in different Brassica spp. In B. oleracea, resistance to race 3 (and other rare races) is common, but resistance to race 1 is very rare (17). The inheritance of these two types of resistance in B. oleracea was elucidated.

Resistance to race 3 in a $\mathrm{DH}$ line derived from cv. Böhmerwaldkohl was controlled by a single dominant locus designated
Xca3 (Table 2). The resistance of PI 436606 is more quantitative, but it might also be controlled by the same single dominant locus. However, to confirm this hypothesis, tests of an $\mathrm{F}_{2}$ population derived from crosses between PI 436606 and $\mathrm{BOH}$ 85c would be necessary. Ignatov et al. (9) attributed the race-specific resistance of a Chinese kale line to some $X$. campestris pv. campestris strains (possibly race 3 ) to a single dominant locus that may correspond to Xca3. However, these authors indicated that PI 436606 was susceptible to strain NCPPB 528 (race 3 in our model) and resistant to strains of another race (possibly race 1 ). Dickson and Hunter (6) suggested that juvenile resistance of PI 436606 was

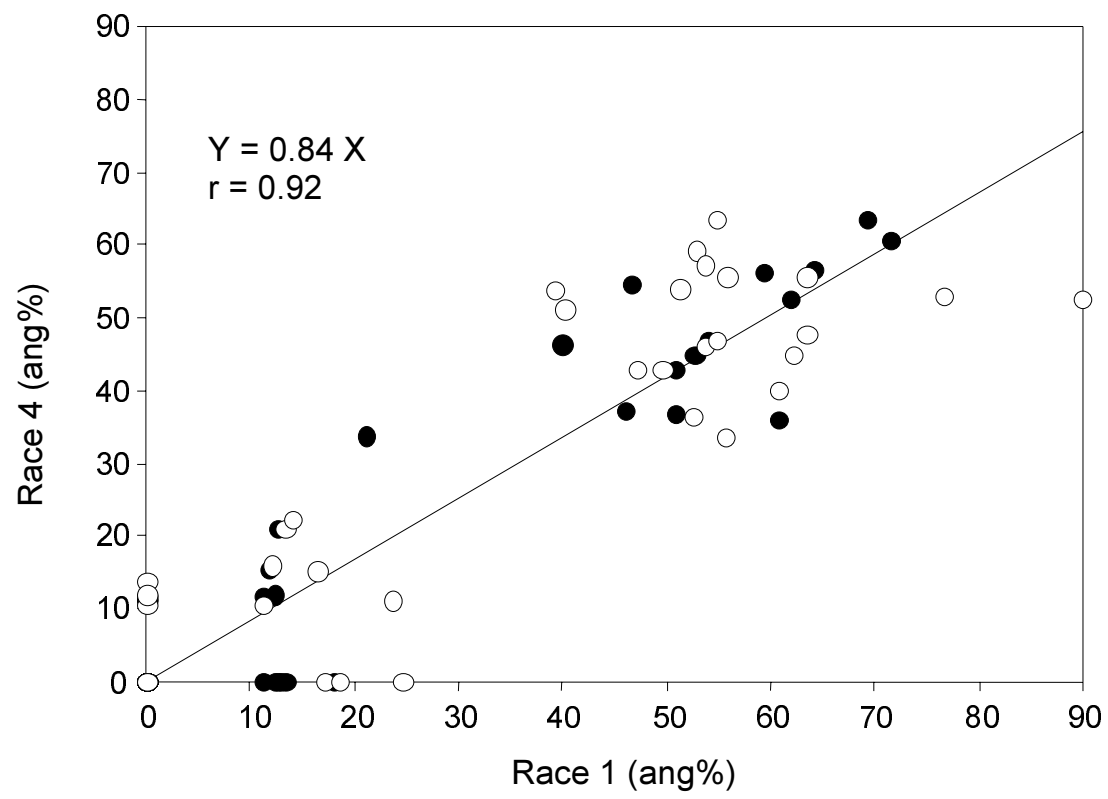

Fig. 2. Relation between the angular transformation of the percentage of points showing disease symptoms in plants of the $F_{2}$ (filled circle) and backcross to the susceptible parent (open circle) populations derived from crosses between Brassica carinata line HRI 6987 and PI 199947 inoculated with races 1 and 4 of Xanthomonas campestris pv. campestris.

TABLE 6. Resistance to Xanthomonas campestris pv. campestris race 4 in segregating Brassica napus populations derived from crosses between N-o-1, Cobra, and CrGC5 with N-o-9

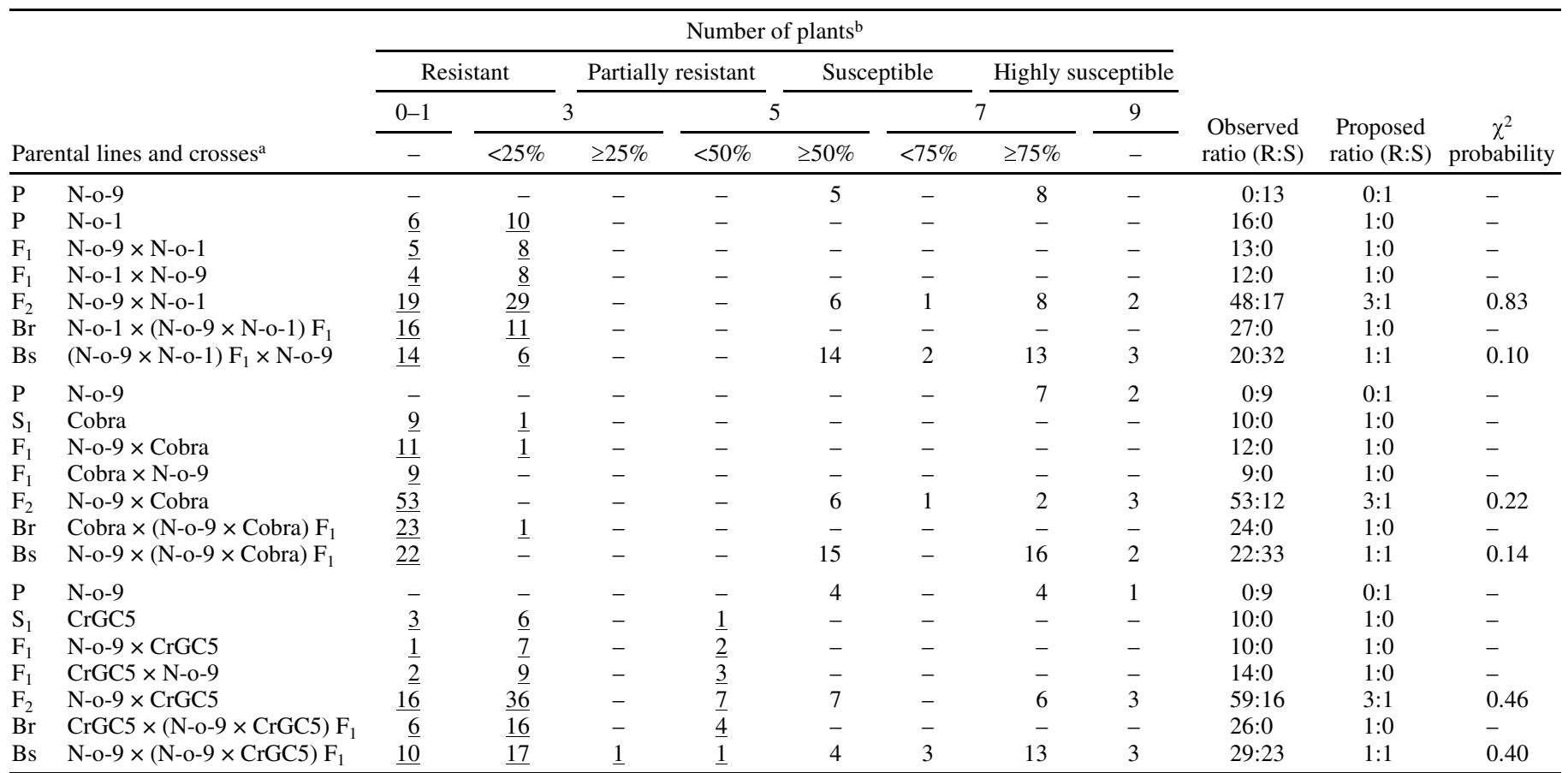

${ }^{a} \mathrm{P}$, parental generation; $\mathrm{S}_{1}$ generation obtained by selfing parental plant; $\mathrm{F}_{1}$, first filial generation; $\mathrm{F}_{2}$, second filial generation; Bs, backcross to susceptible parent; $\mathrm{Br}$, backcross to resistant parent.

${ }^{\mathrm{b}}$ In each class, based on a 0-to-9 scale of severity and percentage of infected points per plant. Underlined plants were considered resistant. 
controlled by a single recessive locus; however, the race of the $X$. campestris strain used by these authors is uncertain. Heterozygosity within the PI 436606 line could have contributed to these discrepancies, because previous studies may have used different selections of this accession.

Resistance to races 1 and 3 was quantitative and recessive in BI-16 (Table 4). Resistance to race 3 was correlated with resistance to race 1 , indicating that resistance to both races is either controlled by the same recessive locus $(x c a 6)$ or by linked loci. Plants were generally more susceptible to race 1 than to race 3 , but this was probably due to a difference in aggressiveness between the two strains. The locus xca6 might correspond to the $f$ gene identified by Williams et al. (25) in crosses with cv. Early Fuji. Our results are in agreement with results reported by Camargo et al. (5) with race 1 . Our work indicates that resistance to race 1 and resistance to race 3 are controlled in a similar way, but Ignatov et al. (9) have suggested that the resistance of BI-16 to two different races (possibly race 1 and 3 ) is controlled by two loci (one dominant and one recessive). Although resistance at 8 weeks appears to be well correlated with resistance at 4 weeks, the results indicate that older plants are more resistant. Resistance to race 1 (and 3) does not appear to assort independently from the locus that controls the color of the flower. The results indicate that although these loci are not very closely linked, they might be situated in the same linkage group.

$B$. carinata (BC genome) and B. napus (AC genome) are amphidiploid species derived, respectively, from interspecific hybridization between $B$. nigra (B genome) and B. oleracea (C genome) and B. rapa (A genome) and B. oleracea (19). Resistance to races 1 and 4 in $B$. carinata appears to be controlled by a dominant locus designated $X c a l$. These results are in agreement with the work of Guo et al. (7), but the strain used by these authors has

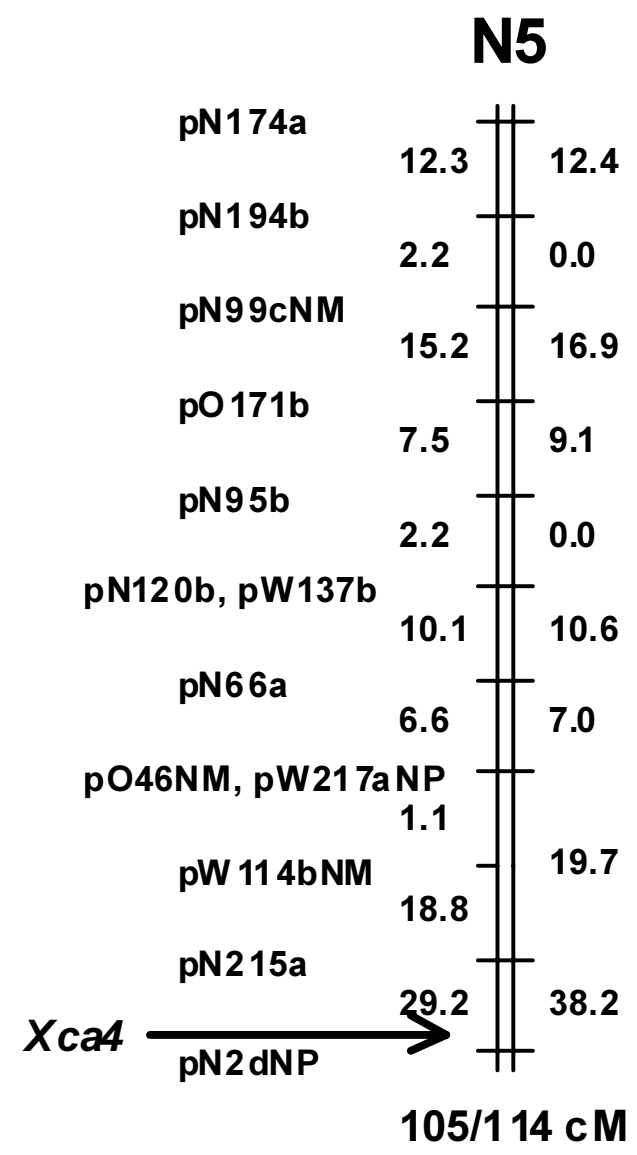

Fig. 3. Location of Xca4 on linkage group N5 of a restriction fragment length polymorphism map of Brassica napus (16). not been race-typed. It is unlikely that the strong resistance to race 1 and 4 in $B$. carinata is related to the quantitative resistance to race 1 found in $B$. oleracea (BI-16). To date, strong resistance to races 1 and 4 has not been found in $B$. oleracea, but is common in $B$. carinata, B. nigra, and B. juncea (17), therefore we hypothesize that this resistance has originated from the $\mathrm{B}$ genome.

Resistance to race 4 in three lines of B. napus is probably controlled by a single dominant locus designated Xca4. The resistance was stronger in a winter rape line derived from $\mathrm{cv}$. Cobra than in the spring rape lines CrGC5 and N-o-1. This effect has also been observed in a number of other spring and winter rape cultivars (17). Resistance to race 4 was found to be common in B. napus and B. rapa (17). Preliminary results of the segregation of self progenies of $B$. rapa cvs. Just Right Turnip and Tokyo Cross Turnip indicated that the resistance to race 4 in $B$. rapa is also controlled by a single dominant locus (data not shown). Our results are in agreement with results reported previously by Ignatov at al. $(10,11)$ in crosses of $B$. rapa and $B$. napus lines.

The locus Xca4 was mapped in the linkage group N5 of the $B$. napus A genome, confirming that the resistance originated from $B$. rapa (21). This is the first major locus for resistance to $X$. campestris pv. campestris to be mapped in Brassica spp.

Our study of the inheritance of resistance to $X$. campestris $\mathrm{pv}$. campestris in Brassica spp. has helped to validate the gene-forgene model proposed by Vicente et al. (20); existence of resistance genes R1, R3, and R4 of the model was confirmed. These genes correspond to the loci Xcal, Xca3, and Xca4. B. oleracea generally seems to lack useful levels of resistance to the most important races (races 1 and 4 ) of $X$. campestris pv. campestris. It should be possible to improve this species by incorporating the race-specific resistance genes $\mathrm{R} 1$ (Xcal), from the B genome, and R4 (Xca4), from the A genome.

\section{ACKNOWLEDGMENTS}

This work was supported by the UK Ministry of Agriculture, Fisheries and Food (MAFF) and the Biotechnology and Biological Sciences Research Council (BBSRC). Part of the work of J. Vicente was supported by a grant from PRAXIS XXI (BD/3780/94). We thank D. Pink and J. Walsh for providing seeds; J. Lynn for assistance with statistical analysis; and J. Conway, B. Everett, and R. McClenaghan for assistance in the glasshouse.

\section{LITERATURE CITED}

1. Bain, D. C. 1952. Reaction of Brassica seedlings to black rot. Phytopathology 42:497-500.

2. Bain, D. C. 1955. Resistance of cabbage to black rot. Phytopathology 45:35-37.

3. Bohuon, E. J. R., Keith, D. J., Parkin, I. A. P., Sharpe, A. G., and Lydiate, D. J. 1996. Alignment of the conserved C genomes of Brassica oleracea and Brassica napus. Theor. Appl. Genet. 93:833-839.

4. Camargo, L. E. A., Savides, L., Jung, G., Nienhuis, J., and Osborn, T. C. 1997. Location of the self-incompatibility locus in an RFLP and RAPD map of Brassica oleracea. J. Hered. 88:57-60.

5. Camargo, L. E. A., Williams, P. H., and Osborn, T. C. 1995. Mapping of quantitative trait loci controlling resistance of Brassica oleracea to Xanthomonas campestris pv. campestris in the field and greenhouse. Phytopathology 85:1296-1300.

6. Dickson, M. D., and Hunter, J. E. 1987. Inheritance of resistance in cabbage seedlings to black rot. HortScience 22:108-109.

7. Guo, H., Dickson, M. H., and Hunter, J. E. 1991. Brassica napus sources of resistance to black rot in crucifers and inheritance of resistance. HortScience 26:1545-1547.

8. Hunter, J. E., Dickson, M. H., and Ludwig, J. W. 1987. Source of resistance to black rot of cabbage expressed in seedlings and adult plants. Plant Dis. 71:263-266.

9. Ignatov, A., Kuginuki, Y., and Hida, K. 1998. Race-specific reaction of resistance to black rot in Brassica oleracea. Eur. J. Plant Pathol. 104:821-827.

10. Ignatov, A., Kuginuki, Y., and Hida, K. 2000. Distribution and inheritance of race-specific resistance to Xanthomonas campestris pv. cam- 
pestris in Brassica rapa and B. napus. J. Russ. Phytopathol. Soc. 1:8994.

11. Ignatov, A. N., Kuginuki, Y., Suprunova, T. P., Pozmogova, G. E., Seitova, A. M., Dorokhov, D. B., and Hirai, M. 2000. RAPD markers linked to locus controlling resistance for race 4 of the black rot causative agent, Xanthomonas campestris pv. campestris (Pamm.) Dow. in Brassica rapa L. Genetika Moskva 36:357-360.

12. Kosambi, D. D. 1944. The estimation of map distances from recombination values. Ann. Eugenet. 12:172-175.

13. Lander, E. S., Green, P., Abrahamson, J., Barlow, A., Daly, M. J., Lincoln, S. E., and Newburg, L. 1987. MAPMAKER: An interactive computer package for constructing primary genetic linkage maps of experimental and natural populations. Genomics 1:174-181.

14. Pink, D., Ockendon, D., and King, G. 1994. Biotechnology in breeding for clubroot resistance in Brassica oleracea. Hortic. Res. Int. Annu. Rep. 1993-94:32-33.

15. Sharma, B. R., Swarup, V., and Chatterjee, S. S. 1972. Inheritance of resistance to black rot in cauliflower. Can. J. Genet. Cytol. 14:363-370.

16. Sharpe, A. G., Parkin, I. A. P., Keith, D. J., and Lydiate, D. J. 1995. Frequent nonreciprocal translocations in the amphidiploid genome of oilseed rape (Brassica napus). Genome 38:1112-1121.

17. Taylor, J. D., Conway, J., Roberts, S. J., Astley, D., and Vicente, J. G. 2002. Sources and origin of resistance to Xanthomonas campestris pv. campestris in Brassica genomes. Phytopathology 92:105-111.
18. Tewari, R. N., Chatterjee, S. S., and Swarup, V. 1979. Inheritance of resistance to black-rot (Xanthomonas campestris (Pam.) Dowson) in cabbage. Vegetable Sci. 6:27-36.

19. U, N. 1935. Genome analysis in Brassica with special reference to the experimental formation of $B$. napus and peculiar mode of fertilization. Jpn. J. Bot. 7:389-452.

20. Vicente, J. G., Conway, J., Roberts, S. J., and Taylor, J. D. 2001. Identification and origin of Xanthomonas campestris pv. campestris races and related pathovars. Phytopathology 91:492-499.

21. Vicente, J. G., Taylor, J. D., Parkin, I. A. P., Sharpe, A. G., Lydiate, D. J., and King, G. J. 1999. Genetics of race specific resistance to Xanthomonas campestris pv. campestris in Brassica oleracea and Brassica napus. Page 182 in: Int. Congr. Mol. Plant-Microbe Interact., 9th. Amsterdam.

22. Westman, A. L., Kresovich, S., and Dickson, M. H. 1999. Regional variation in Brassica nigra and other weedy crucifers for disease reaction to Alternaria brassicicola and Xanthomonas campestris pv. campestris. Euphytica 106:253-259.

23. Williams, P. H. 1980. Black rot: A continuing threat to world crucifers. Plant Dis. 64:736-742.

24. Williams, P. H., and Hill, C. B. 1986. Rapid-cycling populations of Brassica. Science 232:1385-1389.

25. Williams, P. H., Staub, T., and Sutton, J. C. 1972. Inheritance of resistance in cabbage to black rot. Phytopathology 62:247-252. 